\title{
Postpartum intrauterine contraceptive device (PPIUCD) insertion: practices and aftermath at tertiary care centre
}

\author{
Kanchan Rani ${ }^{1 *}$, Nirmal Kumar Pangtey², Garima Khanna², Mahima Rani²
}

\begin{abstract}
${ }^{1}$ Department of Obstetrics and Gynecology, Teerthankar Mahaveer Medical College, Moradabad, Uttar Pradesh, India ${ }^{2}$ Department of Obstetrics and Gynecology, Government Medical College, Haldwani, Uttrakhand, India
\end{abstract}

Received: 28 August 2018

Accepted: 27 September 2018

\author{
*Correspondence: \\ Dr. Kanchan Rani, \\ E-mail: drkanchanrani@gmail.com
}

Copyright: (c) the author(s), publisher and licensee Medip Academy. This is an open-access article distributed under the terms of the Creative Commons Attribution Non-Commercial License, which permits unrestricted non-commercial use, distribution, and reproduction in any medium, provided the original work is properly cited.

\begin{abstract}
Background: According to USAID/ ACCESS 2009 survey, in India, 65\% of women in first year postpartum have an unmet need for family planning. Recommended spacing between birth to next pregnancy is at least 24 months and between abortion to next pregnancy is at least six months (WHO Technical Committee,2006). Pregnancy before 24 months of previous birth increase maternal and perinatal morbidity and mortality. So, during this postnatal period woman must be offered any form of reversible contraceptive. IUCD is most frequently use reversible method of family planning in the world. The aim of present study is to evaluate acceptability safety efficacy and complication of PPIUCD in tertiary care center.

Methods: This is a retrospective study conducted at Government Medical College and Hospital in northern India over a period of 1 year from January 2016 to December 2016. Patients were followed up to 6 months period and their complaints and various parameters were analyzed.

Results: 219 patients were inserted PPIUCD during 1-year period. Acceptance rate was higher in P2 (51.6\%), between 20 to 25 years of age $(47.49 \%)$ followed by $26-30$ years of age $(38.8 \%)$. On follow up $44.3 \%$ had no complaints. Most common complaints were lower abdominal pain (15\%), missing thread (14.6\%) and vaginal discharge (8.2\%). 5.48\% women came for removal of IUCD. Main cause of removal was pressure from family and lower abdominal pain. Expulsion rate was low (2.74\%). There was no case of perforation or failure (pregnancy).

Conclusions: During present study authors found that PPIUCD is highly effective, acceptable, safe and with fewer side effects. PPIUCD is especially beneficial in Indian population where accessibility for contraception is lower during interval period and women do not come for contraception during postpartum period.
\end{abstract}

Keywords: Complications, Intra caesearean, Post placental, PPIUCD

\section{INTRODUCTION}

India is the second most populous country of the world, having $17.5 \%$ of world's population in only $2.4 \%$ of global land mass. This large population size of India not only impacts its own but also the global health indicators. So, India is in dire need of family planning methods. An expert committee of WHO in 1971 defined family planning as "A way of thinking and living that is adopted voluntarily upon the basis of knowledge attitudes and responsible decisions by individuals and couples in order to promote the health and welfare of the family group and thus contribute effectively to the social development of a country". ${ }^{1}$

Another expert committee described, and defined family planning as-Family planning refers to practices that help individuals or couples to attain certain objective: to avoid unwanted births, to bring about wanted births, to regulate the intervals between pregnancies to control the time at which birth occurs in relation to the ages of parents and to determine the number of children in the family. 
The United Nation Conference on human rights at Tehran in 1968 recognized family planning as basic human right. The World conference of the international women's' year 1975 also declared "The right of women to decide freely and responsively on the number and spacing of their children and to have access to the information and mean to enable them to exercise that right". ${ }^{3}$

India is the first country to launch a nationwide family planning programme in 1952. Objectives of family welfare programme in India is that people should adopt the small family norm to stabilize the country's population at the level of some 1,533 million by the year $2050 \mathrm{AD}$.

In the 1970's slogan was "Do Ya Teen Bas". In 1980's it became the two-child norm. The current emphasis is on three things "son or daughter two will do"; "second child after three years"; "Universal immunization". Couple protection rate in India is $50.7 \%$ and unmet need is $12.8 \%$ This unmet need is increased in first year of post-partum to $65 \%$ according to USAID/ACCESS 2009 survey in India.

According to WHO technical committee 2006 recommended spacing between birth and next pregnancy is at least 24 months. Pregnancy before 24 months of birth increases maternal and perinatal morbidity and mortality. It also increases rate of MTP and septic abortion which further impacts on maternal morbidity and mortality.

Women 2-3 months after childbirth are very vulnerable to unwanted pregnancy as exclusive breast-feeding decreases, sexual activity increases and menstruation returns. Family planning can avert nearly one third of maternal death and $10 \%$ of child mortality when couple space their pregnancy more than 2 years apart. ${ }^{4}$ There are various method of postpartum contraception like lactational amenorrhoea, barrier method, progesterone only pill, sterilization and IUCD.

PPIUCD (CuT 380A) has emerged as most cost effective and ideal postpartum contraceptive available as it is highly effective, one-time application, safe, inexpensive, reversible, acceptable, simpler to administer, independent of coitus, no effect on breast feeding, require no or little medical supervision and can serve as both limiting and spacing in some cases. ${ }^{5}$

Recognizing the potential impact of improved family planning programme on maternal and child health, the Government of India has committed to expanding access to family planning as a part of achieving MDG (Millennium development Goals) 4 and 5, related to reduction of maternal and child mortality.

In 2005, the Government of India launched the Janani Suraksha Yojana (JSY); a conditional cash transfer scheme to encourage institutional deliveries. ${ }^{6}$ Since the inception of JSY, facility based birth in public sector have increased from 700,000 in 2005 to more than 11 million in 2012. ${ }^{7}$ With increase in Intuitional delivery Government of India decided to strengthens PPFP and introduced PPIUCD in services in phased manner with $1^{\text {st }}$ batch of clinician training in 2009. National Training Centre was established at Safdarjung Hospital in New Delhi as well as 3 regional training center in Mumbai, Jabalpur and Lucknow in 2009-2010. Provision of PPIUCD is being rapidly scaled up in India with facilities in at least 19 states offering the method in 2013.

PPIUCD are still emerging as relatively new contraception choice in India. Follow up data on complications with PPIUCD insertion were available from international sources but given scale at which PPIUCD services are being introduced in India, It was imperative to generate country based evidence on post insertion outcomes after introduction of PPIUCD programme.

The aim of this study is to evaluate acceptability, safety, efficacy and complications of PPIUCD at tertiary care center.

\section{METHODS}

This retrospective was conducted in department of obstetrics and gynecology at Government Medical College Hospital, Haldwani. It was for duration of 1 year from January 2016 to December 2016.This study included 219 women who were admitted and delivered vaginally or by LSCS and inserted PPIUCD (CuT 380A).

\section{Inclusion criteria}

Women willing for Copper $\mathrm{T}$ insertion and its follow up and meeting all the WHO medical eligibility criteria for Post-partum IUCD Insertion were included in the study.

\section{Exclusion criteria}

Women having unresolved PPH, extensive genital trauma, any abnormality of uterus distorting its cavity, chorioamnionitis or puerperal sepsis, large Fibroid, prolonged rupture of membranes of $>18$ hours, malignant or benign Trophoblastic disease, HIV/AIDS and Pelvic Inflammatory Disease were excluded from study.

Those patients who fulfilled inclusion criteria were counselled and PPIUCD inserted after talking informed consent. IUCD was placed within 10 minutes of delivery of placenta using Kelly's forceps in case of vaginal delivery and ring forceps was used to place IUCD in case of caesarean section. At the time of discharge patient were advised to come for follow up after 6 weeks. Patient were counselled about side effects like foul smelling vaginal discharge, excessive vaginal bleeding, severe lower abdominal pain, fever and expulsion of device and they were advised to report earlier if any of the symptom appear. 
At 6 weeks patient were examined and any complaints were noted and treated. Patients were followed up to 6 months. The observations were noted and analyzed. Various parameters analyzed were age, parity, type of application (whether post-placental or intra-caesarean) spontaneous expulsion, manual removal, reason for removal, side effects and complications and failed contraception.

\section{Statistical analysis}

Statistical evaluation was done using SPSS version 21 and results were presented as percentage.

\section{RESULTS}

A total of 219 patients were inserted PPIUCD. In 143 (69.3\%) PPIUCD were inserted in post placental period and in $76(34.7 \%)$ insertion was during intra-caesarean period (Table 1). Acceptance of PPIUCD was more after normal vaginal delivery as compared to caesarean section.

Table 1: Total number of PPIUCD inserted from January 2016 to December 2016 at GMC, Haldwani.

\begin{tabular}{|lll|}
\hline PPIUCD inserted & No. of patients (n) & Percentage \\
\hline Post placental & 143 & 69.3 \\
\hline Intra-caesarean & 76 & 34.7 \\
\hline
\end{tabular}

Most of the patients were in between age group 20-25 years $(47.49 \%)$ of age followed by $26-30$ years $(47.49 \%)$ of age (Table 2). Present study suggests that PPIUCD acceptance was more in younger age group of patients which gradually declined with increasing age and remained only $5.48 \%$ in age above 35 years.

Table 2: Age group of patients included in the study.

\begin{tabular}{|lll|}
\hline Age (years) & No. of patients (n) & Percentage \\
\hline $20-25$ & 104 & 47.49 \\
\hline $26-30$ & 85 & 38.81 \\
\hline $31-35$ & 18 & 8.21 \\
\hline Above 35 & 12 & 5.48 \\
\hline
\end{tabular}

The acceptance of PPIUCD was higher in multiparous patients $(51.60 \%)$ as compared to primiparous patients $(30.60 \%)$ (Table 3).

Table 3: Parity of patients in study group.

\begin{tabular}{|lll|}
\hline Parity & No. of patients (n) & Percentage \\
\hline Primiparous & 67 & 30.60 \\
\hline Multiparous & 113 & 51.60 \\
\hline Grand multipara & 39 & 17.80 \\
\hline
\end{tabular}

In $44.3 \%$ patients there were no complaints on follow up. However, the most common complaints noted were pain lower abdomen in $15 \%$, missing thread in $14.6 \%$ and vaginal discharge in $8.21 \%$. No failure of PPIUCD i.e. pregnancy was recorded. There was no incidence of uterine perforation in present study (Table 4).

Table 4: Incidence of occurrence of complications (out of 219 patients).

\begin{tabular}{|lll|}
$\begin{array}{l}\text { Complaints and } \\
\text { complications }\end{array}$ & $\begin{array}{l}\text { No. of } \\
\text { patients (n) }\end{array}$ & \begin{tabular}{l} 
Percentage \\
\hline No complaints
\end{tabular} \\
\hline Missing thread & 32 & 44.3 \\
\hline Long thread & 12 & 14.6 \\
\hline Lower abdominal pain & 33 & 5.48 \\
\hline Menorrhagia & 5 & 15 \\
\hline Irregular vaginal bleeding & 12 & 2.28 \\
\hline Cervicogenic discharge & 18 & 5.48 \\
\hline PID & 2 & 8.21 \\
\hline Removal & 12 & 0.9 \\
\hline Expulsion & 6 & 5.48 \\
\hline
\end{tabular}

PPIUCD was removed in 12 cases $(5.48 \%)$ and the most common cause of removal was pain in lower abdomen in $41.67 \%$ followed by family pressure in $33.33 \%$ (Table 5).

\section{Table 5: Causes of removal of PPIUCD as seen in 12} cases $(5.48 \%)$.

\begin{tabular}{|lll|}
\hline Causes & No. of patients (n) & Percentage \\
\hline Pain lower abdomen & 5 & 41.67 \\
\hline Family pressure & 4 & 33.33 \\
\hline PID & 2 & 16.67 \\
\hline Menorrhagia & 1 & 8.33 \\
\hline
\end{tabular}

Out of 12 cases of PPIUCD removal 3 cases $(25 \%)$ needed hysteroscopic removal because PPIUCD threads were not visible. In remaining 9 cases $(75 \%) \mathrm{Cu} \mathrm{T}$ were removed on OPD basis as shown in Figure 1.

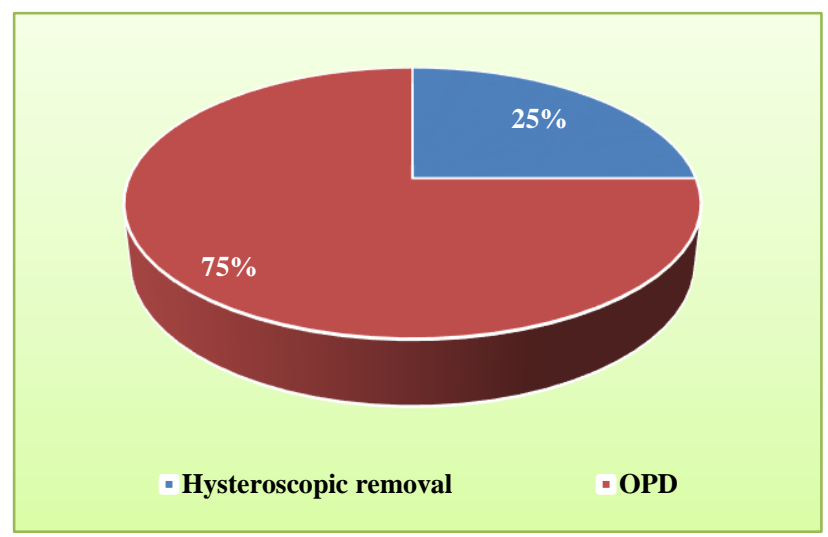

Figure 1: Mode of removal of PPIUCD.

There were $32(14.6 \%)$ reported cases of missing thread in present study. Data suggested that most cases of missing thread $28(87.5 \%)$ were following LSCS and in only $4(12.5 \%)$ cases it was following vaginal delivery (Figure 2). 


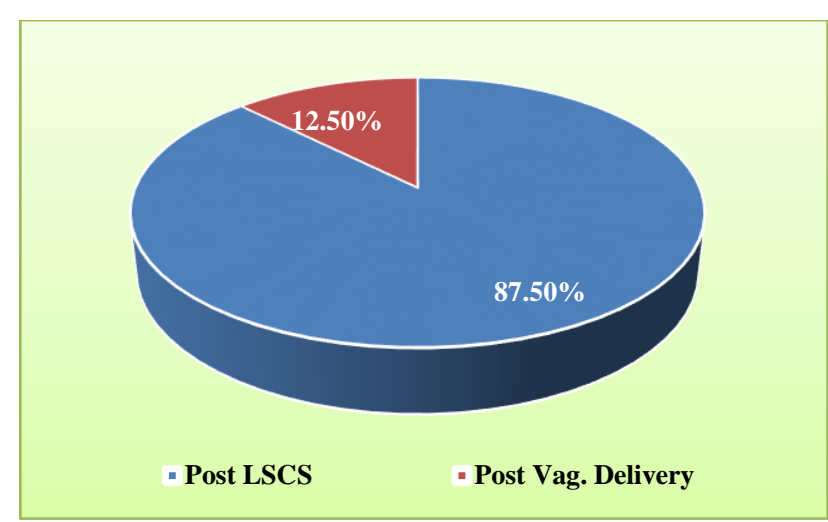

Figure 2: Cases of missing threads.

\section{DISCUSSION}

In present study acceptance rate was highest in women of 20-25 years of age (47.49\%) followed women of 26-30 years of age $(38.81 \%)$. As the age increased acceptance rate decreased i.e. $5.48 \%$ in patients over 35 years of age. It was similar to study conducted Katheit G, and Agarwal and Mishra where acceptance was highest among the age group of 21-25 years of age. ${ }^{8,9}$

Present findings were similar to findings of director of family welfare, Tamil Nadu, India in 2011-2012.59\% of the acceptors were in age group of 20-24 years, $31 \%$ were in the age group of 25-29 years, $6 \%$ in age group of $34-44$ years. But in a study conducted by Malchuru et al from Guntur the highest rate of acceptance was among the age group of 30-39 years $(27.67 \%) .{ }^{9}$ In present study acceptance rate was more in P2 $(51.6 \%)$ followed by P1 $(30.6 \%)$ which is similar to other studies like in Bhalarao and Purandare where acceptance rate in P2 was $69 \%$ and $46 \%$ in $\mathrm{P} 1 .^{10}$

Malchuru et al, Mishra, Gautam et al and Vidyarama et al had an acceptance rate of (15.42\%), (13.76\%), (71.91\%) and $15.47 \%$ respectively in Primipara. ${ }^{9,11-13}$ In a study conducted by DFW Tamil Nadu 2011- 2012 acceptance was highest in primipara (72\%) followed by $25 \%$ in P2 and only $3 \%$ had a higher order of birth.

On follow up $44.3 \%$ had no complaints in present study. $15 \%$ had lower abdominal pain. It was similar to study done by Chen where post insertion cramps were present in $20 \% .{ }^{14}$ In a study conducted by Ajit and Manju at Odisa $5.08 \%$ had abdominal pain. ${ }^{15}$ In present study $2.28 \%$ had menorrhagia which is similar to study conducted by Eroglu (2006) in incidence of excess bleeding was $1.2 \% .^{16}$ Kittur $\mathrm{S}$ noted incidence of excessive bleeding was higher i.e. $6.2 \% .{ }^{17}$ Irregular bleeding incidence in present study was $5.48 \%$.

In present study incidence of missing thread was $14.6 \%$ which is higher than study conducted by Eroglu which reported missing thread incidence of $1.2 \% .{ }^{16}$ It is similar to study conducted by Mishra et al. where incidence of missing thread was $8.69 \% .{ }^{9}$ No perforation or pregnancy i.e. failure was reported in present study. Celen, Chen and Beltagry also had no case of perforation. ${ }^{14,18,19}$ Celen and Eroglu reported $0.2 \%$ and $1.6 \%$ of pregnancy respectively. ${ }^{16,18}$

In present study $2.74 \%$ had expulsion. This incidence is low as compared to a study conducted in Zambia where expulsion rate was $5.6 \% .^{20}$ Mishra and Shobhasmita et al found expulsion rate to be $6.4 \%$ and $6 \%$ respectively. ${ }^{9,21}$

In present study $5.48 \%$ patients came for removal of IUCD. Most common cause for removal was pain lower abdomen (41.67\%) followed by family pressure (33.33\%). Mishra reported $23.26 \%$ of removal was due to family pressure whereas Rungun and Bernoli reported $27.27 \%$ of removal was due to family pressure..$^{9,11,22}$ Excessive bleeding accounted for $16.67 \%$ of cause for PPIUCD removal which is low compared to Rungan and Bernoli (42.11\%) and Mishra (32.56\%) studies. ${ }^{9,22}$

\section{CONCLUSION}

Postpartum women are especially vulnerable to unwanted pregnancy with increase rate of MTP or abortion after taking pill over the counter or septic abortion by untrained person especially in rural areas. Thus, there is increase in maternal morbidity and mortality. Women are highly motivated and receptive to accept family planning methods during post-partum period. Increase in Institutional deliveries all across the country created opportunities for providing quality family planning postpartum services.

PPIUCD has distinct advantages as contraceptive during postpartum period as it is one-time application, provider has assurance that patient is not pregnant at the time of application and it can serve as both spacing and limiting in some cases. Main advantage of post-placental IUCD is that no additional hospital visit is required for insertion of IUCD and no pain on insertion when used post-placental or intra-caesearean. Also, initial cramping due to IUCD is shadowed with pain due to uterine contraction in puerperium. Few side effects which worried the patients were missing thread which occurred mostly after LSCS (due to coiling of thread) which needed USG for localization of $\mathrm{Cu} \mathrm{T}$ and further reassurance. Another problem was women who came for early removal of PPIUCD had to undergo hysteroscopic removal because thread was coiled inside and was not visible to be removed on OPD basis. What authors found in present study was there were lots of misconception regarding IUCD like perforation, migration pain and bleeding problem. Rate of removal was high due to myths and family pressure.

So repeated counselling of patient's husband and family is required during antenatal period for PPIUCD. Patient who come to hospital only for delivery, counselling and incentive by government to both the client and service 
provider will increase the acceptance rate of PPIUCD in developing countries like India where women especially from rural area do not come for post-natal contraception.

\section{Funding: No funding sources}

Conflict of interest: None declared

Ethical approval: The study was approved by the Institutional Ethics Committee

\section{REFERENCES}

1. WHO (1970). Techn. Rep. Ser. No. 442. Available at: https://www.who.int/biologicals/technical_report_series len/.

2. WHO (1975). Techn. Rep. Ser. No. 569. Available at: https://www.who.int/biologicals/technical_report_series len/.

3. United Nations (1975) World Conference of the International Women's Year: World Plan of Action, Document E/C of .66/5, 1975, UN Secretariat. Available https://www.fordlibrarymuseum.gov/library/document/ 0126/1489978.pdf.

4. Cleland J, Bernstein S, Ezeh A, Faundes A, Glasier A, Innis J. Family planning: the unfinished agenda. Lancet. 2006;368:1810-27.

5. Akkuzu G, Vural G, Eroglu K, Dilbaz B, Taskin L, Akin A, et al. Reason for continuation or discontinuation of IUD in post placental/early postpartum periods and post puerperal/interval periods. One year follow up. Turkiye Klinikleri J Med Sci. 2009;29:353-60.

6. Lim SS, Dandona L, Hoisington JA, James SL, Hogan MC, Gakidou E. India's Janani Suraksha Yojana, a conditional cash transfer programme to increase births in health facilities: an impact evaluation. Lancet. 2010 ;375(9730):2009-23.

7. Government of India: All India Summary of National Rural Health Mission Program, 2012. Available at: http://www.nrhm.gov.in/monitoring/progress-ofnrhm.html.

8. Katheit G, Agarwal J. Evaluation of post placental intrauterine contraceptive device (PPIUCD) in terms of awareness, acceptance and expulsion in a tertiary care centre. Int $\mathrm{J}$ Reprod Contracept Obstet Gynaecol. 2013;2:539-43.

9. Mishra S. Evaluation of safety, efficacy, and expulsion of post-placental and intra-cesarean insertion of intrauterine contraceptive devices (PPIUCD). J Obstet Gynaecol India. 2014;64:337-43.

10. Bhalerao AR, Purandare MC. Post-puerperal $\mathrm{Cu}-\mathrm{T}$ insertion. A prospective study. J Prostgrad Med. 1989;35:70.

11. Malchuru S, Arun V, Prabhavathi N. Postpartum intrauterine device insertion- 2 years' experience at tertiary care centre in Gunture Medical College/Govt general hospital, Guntur. J Dent Med Sci. 2015;14:5661.

12. Gautam R, Arya KN, Kharakwal S, Singh S, Trivedi M. Overview of immediate PPIUCD application in Bundelk hand region. J Evol Med Dent Sci. 2014;3:9518-26.

13. Vidyarama R, Nagamani T, Prasad U. PPIUCD as a long acting reversible contraceptive (Larc)-an experience at a tertiary care centre. IJSR. 2012;4:5-7.

14. Chen BA, Hayes JL, Hohmann HL, Perriera LK, Reeves MF, Creinin MD. A randomized trial of postplacental compared to delayed insertion of the levonorgestrel releasing intrauterine device after vaginal delivery. Obstet Gynecol. 2010;116(5):1079-87.

15. Nayak AK, Jain MK. Experience on awareness, acceptability, safety, efficacy, complications and expulsion of postpartum intrauterine contraceptive device insertion. Int J Sci Stud. 2017;5(1):207-12.

16. Eroglu K, Akkuzu G, Vural G, Dilbaz B, Akın A, Taşkın L, et al. Comparison of efficacy and complications of IUD insertions in immediate postplacental/early postpartum period with interval period: 1-year followup. Contracept. 2006;74(5):376-81.

17. Kittur S, Kabadi YM. Enhancing contraceptive usage by PPIUCD insertion with evaluation of safety, efficacy and expulsion. Int $\mathbf{J}$ Reprod Contracept Obstet Gynaecol. 2012;1(1);26-32.

18. Celen S, Moroy P, Sucak A, Aktulay A, Danışman N. Clinical outcomes of early post-placental insertion of intrauterine contraceptive devices. Contracept. 2004;69(4):279-82

19. Beltagy NS, Darwish EA, Kasem MS, Hefila NM. Comparison between cupper T 380 IUD and multiload 375 IUD in early postpartum insertion. Middle East Fert Soc J. 2011;16(2):143-8.

20. Bluementhal P, Shiliya N, Nenkom J. Expulsion rates and satisfaction levels among immediate postpartum IUD users in periurban Lusaka, Zambia. Contracept. 2011;84:320.

21. Shobhasmita B, Anupal S, Alakananda D, Bhattacharjee A, Nabnita D. Acceptance of postpartum intrauterine contraceptive device among women attending Gauhati Medical College and Hospital for delivery between January 2011 to December 2014 and their follow up. J Evol Med Dent Sci. 2015;4:15756-8.

22. Runjun D, Bornali P. A retrospective study on acceptability and complications of PPIUCD insertion. J Evol Med Dent Sci. 2016;5:1631-4.

Cite this article as: Rani K, Pangtey NK, Khanna G, Rani M. Postpartum intrauterine contraceptive device (PPIUCD) insertion: practices and aftermath at tertiary care centre. Int J Reprod Contracept Obstet Gynecol 2018;7:4742-6. 